\title{
Experimental Research on the Bearing Properties of Service Bridge Pile in Loess Soil
}

\author{
Juan HU \\ ${ }^{1}$ College of Urban Construction \\ Zhejiang Shuren University (Hangzhou, China) \\ ${ }^{2}$ Shaanxi Railway Institute \\ Weinan, China \\ e-mail: hujuane_816@163.com
}

\author{
Li SHENG \\ College of Urban Construction \\ Zhejiang Shuren University \\ Hangzhou, China \\ e-mail: 1027811650@qq.com
}

\author{
Minping HU \\ College of Urban Construction \\ Zhejiang Shuren University \\ Hangzhou, China \\ e-mail: 190938125@qq.com
}

\begin{abstract}
Influenced by the dead loads and the cyclic loads of upper structure of bridge over a long period of time, it will have important significance to study the settlement, bearing capacity and skin friction, relations between cyclic loading and the nature of the soil for reconstruction in service period of bridge piles. The fiber gratings (strings) were sticked on the surface of steel pile to form the model pile. Based on the model test, the bearing behavior of pile foundation under vertical cyclic loading is studied systematically. Analyzing the values of settlement of pile top, axial force of pile, side friction of pile and soil stress around the pile embedded in the soil, which revealed the relationship between the test loading times and the characteristics of pile bearing. Fitting the curves of the relationship between the bearing capacity of pile and settlement of pile top with static loading model test in loess soil. And fitting the curves of the relationship between the settlements of pile top and cyclic loads times under the cyclic loading model test in loess soil. And it will provide the supporting method for the practical engineering demand.
\end{abstract}

Keywords-bearing capacity of pile foundation; fiber bragg grating; model test; static load; cyclic loads test

\section{INTRODUCTION}

The most direct and reliable way to study the vertical bearing characteristics of pile foundation is the field test. For the construction of pile foundation, the test conditions are relatively good, can make the field loading test for pile foundation pile test, but for the service, due to the long-term operation, the monitoring data acquisition and strain gauges embedded were not convenient, and the field test is costly, time-consuming, large occupied area, and the key is the pile test is not repetitive, so the collected data is relatively small. Model test has its unique advantages, and it is a common method to study pile foundation problems. Due to the geometry size of the model test is small, so the specimen is made easy, convenient handling, material saving, labor and time, strong pertinence, data acquisition with less interference, high accuracy of the data, the key the same model can be used in a number of different objective tests.

In this paper, it was based on the similarity theory to design the pile soil model, and the vertical static loading and repeated cyclic loading had been done many times for the test of the pile foundation in Loess [1-20], which was to explore the settlement and bearing characteristics of pile foundation under cyclic load.

\section{DESIGN OF MODEL TEST}

\section{A. Design of Model Box}

The size of the model box [16, 21-23] is $2 \mathrm{~m} \times 2 \mathrm{~m} \times 3 \mathrm{~m}$, as shown in figure 1 . The model box is easy to be assembled and disassembled, the model box bottom and the 3 vertical surfaces were designed as $1 \mathrm{~m} \times 1 \mathrm{~m}$ square formed by splicing (shown in Figure 1 (a)), and the other 1 vertical surface was designed as $1 \mathrm{~m} \times 0.5 \mathrm{~m}$ square formed by splicing (shown in Figure 1 (b)). Among them, the border of $1 \mathrm{~m} \times 1 \mathrm{~m}$ square were welded with $100 \times 10$ angle steel and in the square was fixed with 2 layers of $10 \mathrm{~mm}$ thick toughened glass, which was easy to observe the soil filling process and testing process of soil sample.

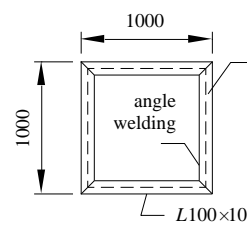

(a) $1 \mathrm{~m} \times 1 \mathrm{~m}$ square

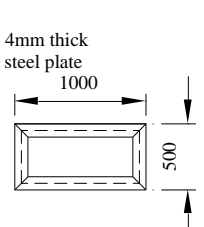

(b) $1 \mathrm{~m} \times 0.5 \mathrm{~m}$ square

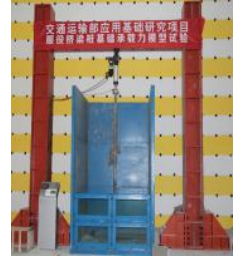

(c) anti-forcing frame
Figure 1. Structure of model test box 


\section{B. Design of Cyclic Loading Device and Anti-forcing Frame}

The test anti-forcing frame was $4 \mathrm{~m}$ wide and $4.5 \mathrm{~m}$ high, which was fixed on the ground of the laboratory with bolts, and installed the servo electric cylinder under the bottom of the cross beam, as shown in Figure 1(c).

\section{Design of Model Pile}

The model piles were steel pipe, and the outer diameter of the steel pipe was $80 \mathrm{~mm}$, the wall thickness was $4 \mathrm{~mm}$. The piles were pasted with 2 pieces of fiber gratings (strings) [24-26] on the pile surface, the wavelength range $(\mathrm{nm})$ was $1525 \sim 1565$. There were 7 grating points every $300 \mathrm{~mm}$ distance along the pile length, as shown in Figure 2. Then the surface was sprayed with a layer of sticky sand to increase the roughness of the model pile.

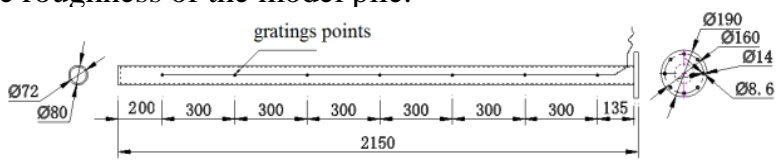

Figure 2. Model test pile

\section{Selection of Soil and Soil Pressure Box Buried}

The loess used in this experiment was taken from the Loess in the high tech campus of Shaanxi Railway Institute, Weinan, Shaanxi. 1 groups of static load tests and 3 groups of cyclic loading tests were carried out, and the experiment were summarized in Table 1.

TABLE I. SUMmaRy TABLE OF STATIC LOAD AND CYCLIC LOADS TEST OF SINGLE PILE IN LOESS

\begin{tabular}{cccc}
\hline No. & $\begin{array}{c}\text { Buried } \\
\mathbf{d e p t h}(\mathbf{m})\end{array}$ & $\begin{array}{c}\text { Cyclic loading } \\
\text { ratio } \boldsymbol{\beta}\end{array}$ & $\begin{array}{c}\text { Cycle times } \\
\left(\times \mathbf{1 0}^{\mathbf{4}}\right)\end{array}$ \\
\hline LST & 2.0 & 0 & 0 (static load $)$ \\
LCT10 & 2.0 & 0.1 & 10 \\
LCT5 & 2.0 & 0.2 & 5 \\
LCT1 & 2.0 & 0.25 & 1 \\
\hline
\end{tabular}

Note: $\beta$ was $P_{\mathrm{c}} / Q_{\mathrm{uk}}, P_{\mathrm{c}}$ was the cyclic loading amplitude and $Q_{\mathrm{uk}}$ was the standard value of vertical ultimate bearing capacity of the single pile.

After the model pile being positioned, the soil was filled by artificial, and were rammed by layered, then the soil was rest for 2 days after filling.

\section{E. Vertical Load Design of Single Pile}

In the cyclic loading test, the loading frequency was $0.2 \mathrm{~Hz}$, and the test was applied to the sine function cyclic load by the servo electric cylinder, as shown in Figure 3.

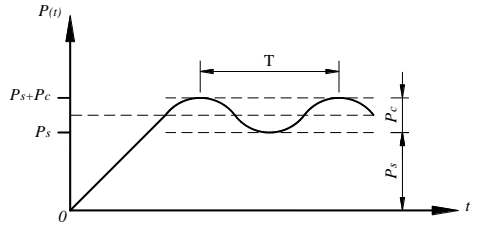

Figure 3. Schematic diagram of cyclic load

$$
P(t)=P_{s}+P_{c} / 2+P_{c} \sin (2 \pi f t) / 2
$$

Among them, the Pc is the cyclic load amplitude, which was determined by the formula (2); Ps is static load, which was determined by formula (3), and $\mathrm{f}$ was the frequency of cyclic loading.

$$
\begin{gathered}
P_{c}=\beta Q_{u k} \\
P_{s}=Q_{u k} / 2-P_{c}
\end{gathered}
$$

Before cyclic loading, according to the requirement of static load test, the model was loaded to Ps step by step, until the settlement of the model pile reached the stable requirement. Then the loads with $\mathrm{Ps}+\mathrm{Pc} / 2$, as a benchmark to start cyclic loading. In the process of cyclic loading, the cyclic loading could be stopped after satisfying the design cycle times. After the cyclic loading test, static load tests were carried out to determine the effect of cyclic loading on the ultimate bearing capacity of the pile.

\section{ANALYSIS OF MODEL TEST RESUlts}

\section{A. Results Analysis of Load Settlement Curve}

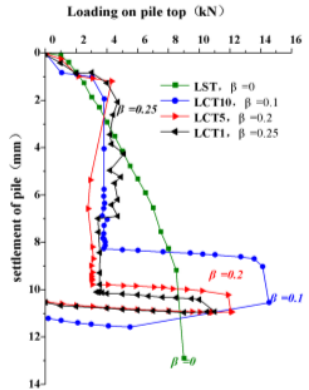

(a)

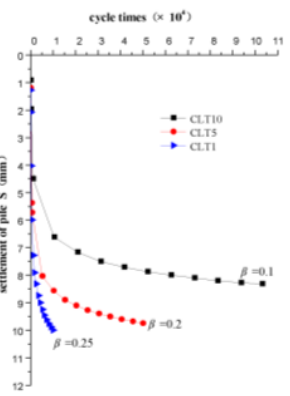

(b)
Figure 4. Settlement curve of single pile top under the vertical static load and cyclic loads

Figure 4(a) was relationship between the pile top settlement and the pile top loading-cyclic loading-unloading. Figure 4 (b) was relationship between pile top settlement and cyclic loading times. As Fig. 4 (a) shown, $Q_{\mathrm{uk}}=8.5 \mathrm{kN}$ and the pile settlement value $S_{\mathrm{uk}}=9.18 \mathrm{~mm}$, and the $Q_{\mathrm{uk}}$ of LCT10, LCT5 and LCT1 was increased $59.4 \%, 29.4 \%$ and $19.4 \%$ respectively than the LST's, and the settlement of LCT10 was reduced by $2.6 \%$, and the settlement of LCT5 and LCT1was increased $10.7 \%$ and $13.6 \%$ respectively than the LST's. Due to the large settlement of pile body in the cyclic loading process, the density of the Loess in the bottom of the pile was increased, which improves the bearing capacity of the pile end.

As Figure 4(b) shown, the settlement of pile was gradually increased with the increase of the number of cycles in the process of cyclic loading. After 100 thousand times of cycle times, the cumulative settlement of pile top was $8.28 \mathrm{~mm}$. After 50 thousand times of cycle times, the cumulative settlement of pile top was $9.64 \mathrm{~mm}$. After 10 
thousand times of cycle times, the cumulative settlement of pile top was $10.09 \mathrm{~mm}$. As the LST test's results, the $Q_{\mathrm{uk}}$ mainly provided by the side friction of the ultimate bearing capacity of pile in loess, and due to load during cyclic loading value was less than the ultimate side friction resistance, so in the early process of cyclic loading, cyclic loading made the pile of soil gradually dense, and it produced large settlement in the process, when the soil compactness was achieved a certain extent, the pile settlement rate had gradually become slow, and tended to be stable.

\section{B. Analysis of the Variation of Pile Tip Resistance and Pile Side Friction Resistance of Loess}

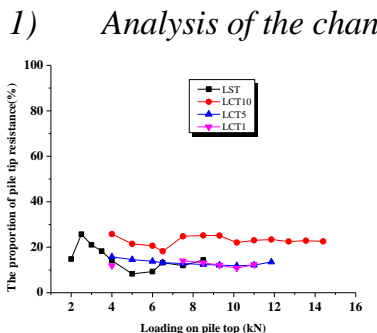

(a)

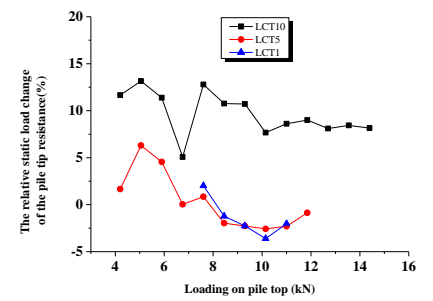

(b)
Figure 5. Change curve of proportion of pile tip resistance in loess

Figure 5(a) was the proportion of pile tip resistance (\%), and Figure 5(b) was the relative static load change of the pile tip resistance (\%). Fig. 5(a) showed that the proportion of the load carrying capacity of pile tip resistance was increasing slightly with the increase of cyclic loading and cyclic loading. As Figure 6(b) showed, static load after the cyclic loading, the pile end resistance with the increase of load ratio became smaller than the LST's, the end resistance changed after 100 thousand cycles of pile, which ranged from 5.07\% to $13.16 \%$; after 50 thousand cycles of pile end resistance changed second, changed in the range of $6.31 \% \sim-2.57 \%$; end resistance changed after 10 thousand cycles minimum pile, which ranged from $2.02 \%$ to $-3.60 \%$.

2) Analysis of the change of pile side frictional resistance:

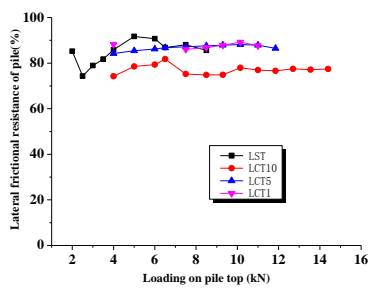

(a)

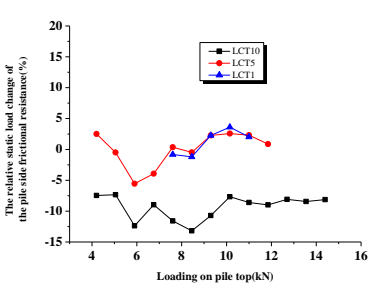

(b)
Figure 6. Change curve of proportion of pile tip resistance in loess

Figure 6(a) was lateral frictional resistance of pile (\%), and Figure 6(b) was the relative static load change of the pile side frictional resistance $(\%)$.

As Figure 6(a) shown, the pile side friction proportion had decreased compared with the static load of side friction of pile for bearing ratio of 100 thousand after cyclic loading static load, 50 thousand times and 10 thousand times after cyclic loading static load pile side friction proportion was almost unchanged. Figure 6(b) showed that, relative to the change trend of end resistance of the pile static loading, in the static load process after cyclic loading, the proportion of pile side frictional resistance increased with the increase of the load. The change range was $-5.07 \% \sim-13.16 \%$ in LCT10, and was $-6.31 \%$ to $2.57 \%$ in LCT5, and was $-2.02 \% \sim 3.60 \%$ in LCT1.

\section{Analysis of the Relationship between the Bearing Capacity of Pile Foundation Test and the Relationship between the Ratio of Bearing Capacity and the Beta and $N$}

The side friction and end resistance of the piles obtained by this model test were contrasted with the calculated bearing capacity by section 5.3 .3 formula [38], which would get the fitting formula as follows:

$$
\gamma=1.0032+0.5453 \beta-0.0319 n
$$

Thereinto $\gamma$ was ratio between bearing capacity and bearing capacity of pile foundation test. $\beta$ was cyclic loading ratio, $\beta$ were $0,0.1,0.2,0.25$. $\mathrm{n}$ was load cycle times, Unit (ten thousand times ), n were $10,5,1$.

\section{CONCLUSION}

This paper focused on the research of pile vertical cyclic loading test, according to test requirements, and completed the development of pile vertical cyclic loading test system, and the Loess of single pile under vertical static load test and 3 vertical cyclic loading tests. The standard value of ultimate bearing capacity of pile in loess was determined by the static load test, and the static load and cyclic load amplitude of cyclic loading test were determined based on the static load test. According to the analysis results, it could be concluded that the cyclic loading had a great influence on the bearing performance of the pile.

(1) In the static load test of pile, the load settlement curve was the descending type; settlement curve is steep in the static load after cyclic loading. After cyclic loading, the settlement of the pile top was increased with the increase of the amplitude of cyclic loading.

(2) Cyclic loading could improve the ultimate bearing capacity of single pile. When the addition value of static loading and cyclic loading was not exceed the characteristic value of single pile bearing capacity, the value of amplitude was improved smaller with the increasing amplitude of cyclic loading. The reduction of side friction of pile body caused by cyclic loading process, accordingly, the proportion of the pile end resistance was improved. The more cycle times, the more the pile side frictional resistance decreased, the greater the proportion of the pile end resistance.

(3) Under the cyclic loading test system, based on fiber grating (string) test technology for the steel pipe pile model test, it fitted the relation curve between the model test of bearing capacity and standard method calculated, and established the experimental conditions of model test of bearing capacity and calculation method of the specification. 
In order to provide reference for the design of bearing capacity of bridge pile foundation in the Loess area.

\section{ACKNOWLEDGMENT}

This research was partially supported by Zhejiang shuren university talent introduction project (2016R001) and the Shaanxi Provincial Department of education project (15JK1168) and the Ministry of transport application foundation research project (2012-319223020) and supported by the fundamental research funds for the Central Universities (NATURAL SCIENCE) (2013G1502019). The first author was supported by Zhejiang Shuren University and Shaanxi Railway Institute. Both sources of support are gratefully acknowledged.

\section{REFERENCES}

[1] Zeng Youjin, Zhang Weimin, Wang Nianxiang, etc. Status of Model Pile Test [J]. Rock and Soil Mechanics, 2003, S2:674-680+686.

[2] POULOS H G. Cyclic axial loading analysis of piles in sand [J]. Journal of Geotechnical Engineering, 1989, 115(6):836-852.

[3] Karlsrud K, Mahan A. Evidence of long term ageing effects on axial capacity of piles in soft clay [C]. Proceedings of The art of foundation engineering practice congress 2010, ASCE: New York, 2010.

[4] CHEN Lan-yun, CHEN Yun-min, ZHANG Wei-min. Time-effect on vertical bearing capacity of single drilled grouting pile in saturated soft soil [J]. Rock and Soil Mechanics, 2006, 27(3): 471-471.

[5] CHEN Zhi-jian, LIU Yan-jun. Model experimental research on compacting effect of concreting for over length and large-diameter bored pile [J]. Rock and Soil Mechanics, 2008, 29(2): 3277-3281.

[6] Xu He, Chen Zhuchang, Ren Chenbao. Experimental study of model pile under axial cyclic loading in sand [J]. Yantu Gongcheng Xuebao, 1989, 11(4): 64-71.

[7] Chen Zhuchang, Xu he. Effect of soil type with axial piles under cyclic loading Characters [J]. Journal of Tongji University, 1989, 17(3): 329-336.

[8] ZHU Bing, REN Yu, CHEN Renpeng. Model test on bearing capacity and accumulated settlement of single pile subjected to axial cyclic loading [J]. Chinese Journal of Geotechnical Engineering, 2009, 31(2):186-193.

[9] CHEN Renpeng, REN Yu, CHEN Yunmin. Experimental investigation on a single stiff pile subjected to long-termaxial cyclic loading[J]. Chinese Journal of Geotechnical Engineering, 2011, 12:1926-1933.

[10] A.M. Trochanis, A.M. ASCE, J. Bielak, M.ASCE, and P.P. Christiano. Hysteretic Dissipation of Piles under Cyclic Axial Load [J]. Journal of Geotechnical Engineering, 1987, 113(4): 335-350.

[11] C. Y. Lee. Cyclic Response of Axially Loaded Pile Groups [J]. Journal of Geotechnical Engineering, 1993, 119(9):1399-1413.
[12] Riadh H. Al-Dou G. Harry G. Poulos. Predicted and Observed Cyclic Performance of Piles in Calcareous Sand [J]. Journal of Geotechnical Engineering, 1995, 121(1):1-16.

[13] Z. Li, S. K. Haigh \& M. D. Bolton. The Behavior of a Single Pile under Cyclic Axial Loads [J]. Deep Foundations and Geotechnical in Situ Testing, 2010:143-148.

[14] Maosong Huang, Ying Liu and Shuai Li. Calculations of Axial Pile Capacity under Sustained Cyclic Loading for Offshore Wind Turbine Foundations [J]. GeoCongress 2012: 4299-4308.

[15] Paul Doherty, Kenneth Gavin. Cyclic and Rapid Axial Load Tests on Displacement Piles in Soft Clay [J]. Journal of geotechnical and Geoenvironment Engineering, 2012, 138(8): 1022-1026.

[16] Juan Hu, Yi Fan Song, Zuo Long Luo. Research Status of Modeling Test on Pile Foundation of Existed Bridge [J]. Applied Mechanics and Materials 2014, 488-489: 377-380.

[17] A. Saimoto and M.H. Aliabadi. Fracture and Damage Mechanism of RC Pile Group Foundation under Low Reversed Cyclic Loading [J]. 2010, Key Engineering Materials, 452-453: 665-668.

[18] Z. Li, S. K. Haigh \& M. D. Bolton. The Behavior of a Single Pile under Cyclic Axial Loads [J]. Deep Foundations and Geotechnical in Situ Testing, 2010:143-148.

[19] Maosong Huang, Ying Liu and Shuai Li. Calculations of Axial Pile Capacity under Sustained Cyclic Loading for Offshore Wind Turbine Foundations [J]. GeoCongress 2012: 4299-4308.

[20] Paul Doherty, Kenneth Gavin. Cyclic and Rapid Axial Load Tests on Displacement Piles in Soft Clay [J]. Journal of geotechnical and Geoenvironment Engineering, 2012, 138(8): 1022-1026.

[21] Juan Hu, Yi Fan Song, Zuo Long Luo. Research Status of Modeling Test on Pile Foundation of Existed Bridge [J]. Applied Mechanics and Materials 2014, 488-489: 377-380.

[22] ZHANG Min, WANG Xinghua, YANG Guangcheng, etc. Study of dynamic model testing of single pile and behaviors of pile-soil interface under cyclic load [J]. Rock and Soil Mechanics, 2013, 04:1037-1044.

[23] HU Juan, SONG Yi-fan, HE Shuanhai. Research on model tests of bearing capacities for composite pile foundation under static and cyclic loading in sand [J]. Journal of Dalian University of Technology, 2015, 03:305-311.

[24] Guo Xian, Yu Fei, Lu Hui. Influence of gauge length on exterior strain measure of concrete in static stress [J]. Electronic Measurement Technology, 2010, 33(1): 89-91.

[25] PAN Hong-liang, HE Jun, YANG Kan. New Method on Scouring Sensor Based on FBG [J], Instrument Technique and Sensor, 2010, $07: 10-12+15$

[26] QIU Rendong, GAO Wensheng, SUN Junjie. Application of fiber bragg grating sensor to lateral load tests of PHC pipe piles [J]. Chinese Journal of Rock Mechanics and Engineering, 2013, 12:25832589 . 